\title{
Obesity, Inflammation, and Severe Asthma: an Update
}

\author{
Varun Sharma ${ }^{1,2} \mathbb{( D} \cdot$ Douglas C. Cowan ${ }^{1,2}$
}

Accepted: 2 December 2021 / Published online: 18 December 2021

(c) The Author(s) 2021

\begin{abstract}
Purpose of Review Obesity-associated difficult asthma continues to be a substantial problem and, despite a move to address treatable traits affecting asthma morbidity and mortality, it remains poorly understood with limited phenotype-specific treatments. The complex association between asthma, obesity, and inflammation is highlighted and recent advances in treatment options explored.

Recent Findings Obesity negatively impacts asthma outcomes and has a causal link in the pathogenesis of adult-onset asthma. Imbalance in the adipose organ found in obesity favours a pro-inflammatory state both systemically and in airways. Obesity may impact currently available asthma biomarkers, and obesity-associated asthma specific biomarkers are needed. Whilst surgical weight loss interventions are associated with improvements in asthma control and quality of life, evidence for pragmatic conservative options are sparse. Innovative approaches tackling obesity-mediated airway inflammation may provide novel therapies.

Summary The immunopathological mechanisms underlying obesity-associated asthma require further research that may lead to novel therapeutic options for this disease. However, weight loss appears to be effective in improving asthma in this cohort and focus is also needed on non-surgical treatments applicable in the real-world setting.
\end{abstract}

Keywords Asthma $\cdot$ Obesity $\cdot$ Inflammation $\cdot$ Weight loss

\section{Introduction}

Asthma remains common, is characterised by variable symptoms and airflow obstruction, and is associated with a significant global health burden [1]. The UK continues to rank highly in obesity prevalence internationally $(8.1 \%$ of UK 15-19-year-olds with obesity in 2015 [2]), has one of the highest asthma mortality rates in Europe, and has disproportionately increased asthma mortality in young people compared to other European countries [2, 3]; for example, the UK asthma mortality rate for ages 20-24 per 100,000 in 2016 was 0.30 (95\% CI 0.28-0.33), compared

This article is part of the Topical Collection on Asthma

Varun Sharma

varun.sharma@ggc.scot.nhs.uk

$\bowtie$ Douglas C. Cowan

douglas.cowan@ggc.scot.nhs.uk

1 Institute of Infection, Immunity and Inflammation, University of Glasgow, Glasgow, UK

2 Glasgow Royal Infirmary, Glasgow, UK to the same age-specific population in Italy with mortality rate 0.03 (95\% CI 0.02-0.05) [2]. Asthma associated with obesity is a particular challenge, being less steroidresponsive and linked to poorer control, increased medication use, longer hospital stays, poorer quality of life, and greater severity of disease [4-9]. Moreover, other obesityassociated comorbidities such as obstructive sleep apnoea syndrome (OSAS) appear to worsen outcomes [10]. In this review, we provide an update on associations between obesity and asthma, current understanding of potential immunological mechanisms, recent interventional trials, and possible future therapies.

\section{Obesity}

Over 650 million adults are obese worldwide [11]. The rising obesity epidemic over the past few decades has led to increased pressure on healthcare resources and rising morbidity and mortality from obesity-associated disease. Obesity impacts on outcomes in many of the most common lung diseases including chronic obstructive pulmonary disease (COPD), asthma, OSAS, and obesity hypoventilation 
syndrome (OHS) [12]. The effect of obesity in pulmonary disorders is multifaceted. Obesity alters chest wall dynamics with mass effect directly affecting thoracic mechanics, an integral component of the process of ventilation. Raised body mass index (BMI) is associated with increased airflow limitation; for example, a recent Danish cross-sectional study showed OR 3.1 (95\% CI 1.97-4.78, $p<0.001)$ and OR 1.7 (95\% CI 1.08-2.68, $p=0.023$ ) for airway obstruction in overweight and obese subjects respectively [13].

Airway closure is associated with gas trapping and hyperinflation and is one of two elements in $\mathrm{FEV}_{1}$ reduction (alongside airway narrowing). In asthma, raised BMI has recently been shown to affect airway closure independently of asthma control [14]. A further study has shown that raised BMI, but not waist circumference (WC, a marker of central obesity), worsens airway closure in people with asthma ( $p=0.01)$, suggesting the effect is not entirely related to altered chest mechanics [15].

Dietary changes associated with obesity, such as highsugar, high-fat, and low-fibre intake, are also associated with increased airway inflammation, at least in murine models $[16,17]$.

\section{Asthma and Obesity: Cause and Effect}

The association between obesity and asthma has historically been considered uni-directional; people with severe asthma become less active and deconditioned, weight increases, and increased usage of oral corticosteroids (OCS) further aggravates the weight gain cycle. Whilst this cohort of patients undeniably exists, increasing evidence supports the causal link between raised BMI, asthma, and poor asthma control (Table 1 [18-37]). Cluster cohort studies show a now widely recognised female-predominant obese severe asthma phenotype [38-40], particularly affecting peri- and post-menopausal women [37]. However, a large cross-sectional US study has shown higher levels of oestradiol (OR 0.43 for current asthma, 95\% CI 0.23-0.78) and testosterone (OR 0.59 for current asthma, 95\% CI 0.37-0.91) appearing to play a protective role in obese asthma [41•]. The links between obesity and asthma are complex and perhaps best considered to be bi-directional [24]. Poorer asthma control and quality of life, increased corticosteroid use, and emergency service attendance in this patient cohort have been demonstrated in numerous studies worldwide [7, 19, 20, 26, 27, 31].

Obesity has been shown to increase inflammation in people with and without asthma [42•, 43••]. A large Japanese genome-wide association study ( $n=9789,4 \%$ with asthma) [43.•] found increasing BMI correlates with increased blood neutrophil and eosinophil count (until BMI approximately $40 \mathrm{~kg} / \mathrm{m}^{2}$ when eosinophil counts levels off). However, another interesting find from this study was that those with an elevated eosinophil level at baseline had a negative association with increasing BMI, suggesting deeper complexity in the relationship between adipose excess and inflammation. A recent European prospective study $(n=202)$ reported an additive effect of asthma and obesity on increased release of pro-inflammatory mediators and airway inflammation as well as modification of the gut, nasal, oral, and lung microbiome, intimately linked with inflammation [42•]. Use of SPECT/CT scanning in obese-asthma has recently shown increased lung eosinophil uptake compared to healthy BMI counterparts further emphasising the impact of obesity on airway inflammation [44]. The presence of dietary polyunsaturated and saturated fatty acids increase release of inflammatory cytokines during respiratory tract infection which may enhance airway inflammation and therefore impact severity of asthma exacerbation [45].

Raised BMI also impacts airways directly through increased airway hyper-responsiveness in populations with asthma [46], and effects on human airway smooth muscle are exaggerated in the obese female adult population [47].

The relationship between increased adiposity and asthma becomes more complicated as visceral adiposity, independent of BMI or waist circumference, affects asthma-related quality of life [48]. Reasons for this include reduced lung function, and increased effects of related comorbidities such as acid reflux and depression; however, the intricate science of adipose tissue and its relationship to inflammation will undoubtedly be important. Further evidence exists to support the argument that obesity-related comorbidities, particularly presence of the metabolic syndrome, also contribute to poorer asthma outcomes [49]. Central obesity, evidenced by raised waist-to-height ratio, and insulin resistance negatively impact lung function in patients with asthma [50].

\section{Adipose Tissue and Inflammation}

Adipose tissue is categorised as "brown" (adipocytes with high mitochondria count and numerous small lipid droplets), "white" (few mitochondria and a large single lipid droplet), or "brown-like" or "beige" (intermediate mitochondria and lipid droplet count compared to white or brown adipocytes) [51] and accumulates to form brown adipose tissue (BAT), white adipose tissue (WAT), and beige adipose tissue respectively. A more recently recognised but less well understood peri-vascular adipose tissue (PVAT) has been documented (Table 2) [52, 53]. Adipose "tissue" forms a complex endocrine organ intimately involved in inflammation homeostasis and is not merely an inert energy reservoir as previously thought. Excessive WAT, seen in obesity, plays a pro-inflammatory role, though healthy BAT acts to regulate these negative effects. However, a process of "browning" WAT (i.e., production of beige adipose tissue) can negate the 


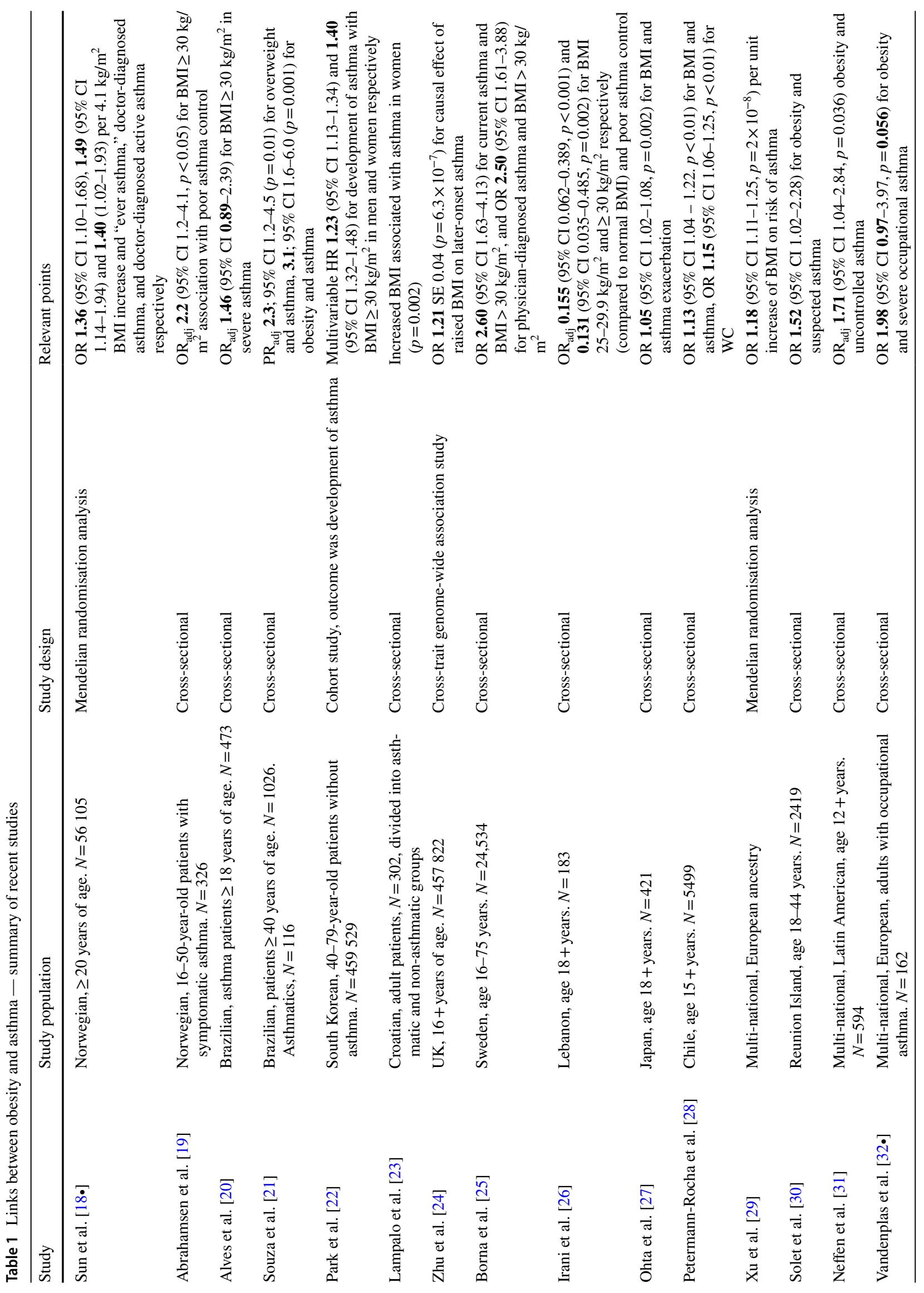




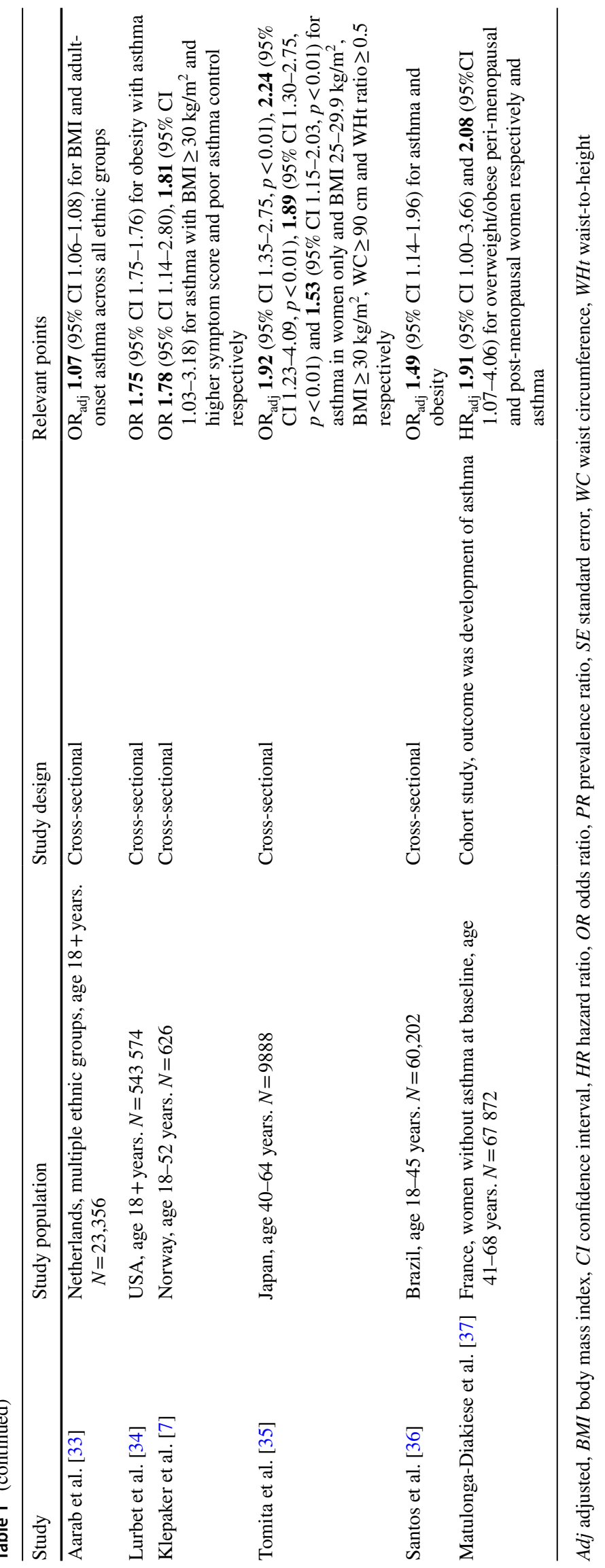


Table 2 Summary of adipose tissue anatomical location and function

\begin{tabular}{lll}
\hline Component & Location & Function \\
\hline BAT [52, 53] & $\begin{array}{c}\text { Predominantly interscapular and subscapular regions, } \\
\text { supraclavicular, neck, peri-renal, mediastinal }\end{array}$ & $\begin{array}{c}\text { Primarily non-shivering thermogenesis, oxidative metabolism. } \\
\text { Evidence of autocrine and paracrine signals promoting BAT } \\
\text { recruitment. Evidence of endocrine signals, e.g., secretion } \\
\text { of insulin-like growth factor 1 improving glycaemic control, } \\
\text { counteracting WAT-induced inflammation and pro- } \\
\text { inflammatory adipokine secretion }\end{array}$ \\
$\begin{array}{cll}\text { WAT [52, 53] } \\
\text { Beige adipose } \\
\text { tissue [52, }\end{array}$ & $\begin{array}{c}\text { Within WAT, predominantly subcutaneous } \\
\text { 53] }\end{array}$ & $\begin{array}{c}\text { Energy storage. Endocrine functions - secretion of leptin, } \\
\text { adiponectin, IL-6, TNF } \alpha\end{array}$ \\
PVAT [52] & Peri-vascular & $\begin{array}{c}\text { Unclear but can display functions of BAT and WAT } \\
\text { (thermogenesis, energy storage) }\end{array}$ \\
& & $\begin{array}{c}\text { Unclear but involvement with regulating vascular tone and } \\
\text { thermogenesis. Can appear similar to BAT or WAT }\end{array}$ \\
\hline
\end{tabular}

$B A T$ brown adipose tissue, $I G F$ insulin-like growth factor, $I L$ interleukin, $P V A T$ peri-vascular adipose tissue, $T N F$ tumour necrosis factor, $W A T$ white adipose tissue

pro-inflammatory effects of WAT also [53]. As such, BAT and beige adipose tissue can be thought of as "protective" against pro-inflammatory states, whilst excess WAT enhances inflammation. Furthermore, BAT activity is reduced in obesity (so called "whitening" of BAT), with increased dysfunctional mitochondria suggested as a factor $[54,55]$. Further understanding is needed in this area; however, there is a relationship between the immune system and adipose tissue with activated macrophages and CD8 + T cells identified as important players [56]. Upregulation of BAT or browning of WAT may have a role to counteract the low-level systemic inflammation caused in obesity. Following bariatric surgery, adipose tissue composition can significantly change with increased BAT and increased browning of WAT associated with an improved inflammatory state post-operatively [57].

Key cytokines produced from adipose tissue have been identified that may be useful as novel biomarkers in management of obesity and obesity-associated inflammatory disease [58]. A summary of effects is provided in Table 3 [59-62].

Increased leptin and IL-6 levels in asthma patients have recently been identified in several studies, strengthening

Table 3 Key adipokines - normal function and effects in obesity

\begin{tabular}{|c|c|c|}
\hline Peptide & Function & Effect in obesity \\
\hline Leptin [59] & Hypothalamic regulation of feeding behaviour & $\begin{array}{l}\text { Increased. Resistance of feeding-behaviour effects. Pro- } \\
\text { inflammatory cytokine production and activation of } \\
\text { monocytes and macrophages }\end{array}$ \\
\hline Adiponectin $[59,60]$ & $\begin{array}{l}\text { Insulin, glucose and fatty acid homeostasis. Anti- } \\
\text { inflammatory and immunomodulatory actions }\end{array}$ & Reduced secretion \\
\hline IL-6 $[59,60]$ & $\begin{array}{l}\text { Insulin, fatty acid homeostasis and effects on energy } \\
\text { expenditure. Can act as pro- or anti-inflammatory }\end{array}$ & Increased secretion, increased pro-inflammatory effects \\
\hline $\mathrm{TNF} \alpha[59,60]$ & $\begin{array}{l}\text { Mediates tumour necrosis. Pro-inflammatory. Increased } \\
\text { lipolysis and decreased insulin signalling }\end{array}$ & Increased secretion \\
\hline Resistin $[59,60]$ & Unclear. Increases insulin resistance & $\begin{array}{l}\text { Increased secretion. Increased pro-inflammatory cytokines, } \\
\text { increases pulmonary inflammation }\end{array}$ \\
\hline IL-10 [60-62] & $\begin{array}{l}\text { Immunomodulatory effects. Reduces pro-inflammatory } \\
\text { cytokine synthesis and decreases macrophage activity. } \\
\text { Reduces release of reactive oxygen species and cytotoxic } \\
\text { T-cell response }\end{array}$ & $\begin{array}{l}\text { Conflicting reports of both high and low levels in obesity } \\
\text { compared to healthy BMI. One suggested explanation } \\
\text { for high levels in obesity is of a homeostatic attempt to } \\
\text { inhibit other pro-inflammatory adipokines. The presence } \\
\text { of metabolic syndrome associated with reduced IL-10, } \\
\text { irrespective of the presence of obesity }\end{array}$ \\
\hline CCL2 $[59,60]$ & Immunomodulatory effects in adipose tissue & Increased pro-inflammatory effects \\
\hline Chemerin [59] & $\begin{array}{l}\text { Immunomodulatory effects, pro-inflammatory but has } \\
\text { potential anti-inflammatory effects. Role in adipocyte } \\
\text { metabolism }\end{array}$ & Increased pro-inflammatory effects \\
\hline
\end{tabular}

$B M I$ body mass index, $C C L 2$ CC-chemokine ligand 2, IL interleukin, $T N F$ tumour necrosis factor 
the link of these pro-inflammatory cytokines with airway inflammation in asthma [63-65].

\section{Obese-Asthma and a Need for Biomarkers}

Routinely used markers of allergy and eosinophilic inflammation in asthma include serum total IgE, fractional exhaled nitric oxide (FeNO), and serum and (where available) sputum eosinophils. Evidence suggests that obesity may have direct effects on these biomarkers, and this has implications for accuracy of phenotyping and determination of suitability for currently available biologic treatments $[66,67]$. Previous studies have shown that increased BMI is negatively correlated with FeNO and this may be related to the increased airway oxidative stress associated with obesity $[68,69]$. More recently, Winnica et al. [70••] found that respiration at a mitochondrial level varies in obese-asthma, when compared to obese controls, healthy BMI-asthma, and healthy BMI controls, with diminished cellular nitric oxide (NO) bioavailability in this cohort resulting in reduced FeNO.

One US multi-centre study [71•.] of 652 adults with mild to moderate asthma revealed poor correlations between increased BMI and the four measured type 2 (T2) inflammatory markers (FeNO, IgE, sputum, and serum eosinophils). FeNO levels were reduced in obese-asthma and, despite $>85 \%$ of participants having positive skin prick testing, IgE levels were also reduced in this group compared to their healthy BMI counterparts. Serum eosinophils, total IgE, and FeNO did not correlate with sputum eosinophilia levels in obesity-associated asthma. The differences seen compared to leaner individuals is perhaps related not only to the increased oxidative stress caused by obesity but also to direct disruption of eosinophil recruitment and survival caused by adipocytokines [71••].

Whilst much research has focussed on biomarkers and treatment options for asthma with T2-high inflammation, it remains widely appreciated that further research is needed to elucidate potential biomarkers and treatment options for the non-T2 and/or T2-low endotypes and this may be particularly relevant to obesity-associated asthma [72-76].

\section{Management of Obesity-Associated Asthma: Scope of the Problem}

In an era of precision medicine, there remains a dearth of specific treatments for obesity-associated severe asthma. Standard current treatment options comprise escalation of historically available asthma therapies, i.e., inhaled corticosteroids (ICS), long-acting beta-agonists (LABA), longacting muscarinic antagonist (LAMA), leukotriene receptor antagonists, oral theophylline, macrolides and OCS, and more recently available biologic treatments (if eligible). Identification and treatment of treatable traits have more recently been encouraged in the management of asthma; however, there remains a paucity of interventions for T2-low or non-T2 severe obese-asthma. Beyond advising healthy living and referring to local weight management services, there are limited choices for dealing with this "treatable" trait.

Despite the wealth of evidence showing positive impacts of bariatric surgery, access to this remains poor for a variety of reasons [77], and surgical risk is not insignificant. Conservative interventions are needed for those in whom surgical options are not appropriate or desired.

Advanced obese-asthma therapies are limited, and there is a need for precision biomarkers that can be used to target specific interventions.

\section{Weight Reduction Strategies in Asthma: Lifestyle and Surgical Interventions}

Further recent studies have evaluated the impact of weight loss strategies on obesity-associated asthma, and in particular the effects of bariatric surgery (Table 4 [78-86]). Surgical techniques, such as Roux-en-Y gastric bypass and sleeve gastrectomy, are associated with reduction in both systemic and airway pro-inflammatory markers, improvement in lung function, asthma control and quality of life scores (including ACT, ACS, AQLQ), and a reduction in treatment burden [78-81]. Some evidence suggests that asthma remission may also result, but this needs to be confirmed [82, 83]. Whilst these studies have limitations including small sample size and open-label design, the available evidence is that bariatric surgery may lead to improvements in outcomes in obese asthma, many of which may be sustained in the mid-to-long term. In contrast, another study by Forno et al.[81] showed a lack of improvement, following bariatric surgery in obesity-associated asthma with concomitant metabolic disease (defined as three out of five of the following: abdominal obesity, raised triglycerides, low HDL, hypertension, and hyperglycaemia). This implies that this phenotype of obese asthma is particularly difficult to treat, and that weight loss alone may not be effective in these patients; a multifaceted, individualised, and targeted approach may be necessary.

An open-label, prospective study [84] utilising diet and a structured exercise program for three months in 51 obese women with physician-diagnosed moderate to severe asthma showed that, alongside improvements in lung volumes and airflow on exertion, loss of $>5 \%$ of body weight had a favourable impact on asthma biomarkers (FeNO), systemic biomarkers (reduced IL-2, IL-4, increased IL-10), and patient-centred outcomes (ACQ, AQLQ). 


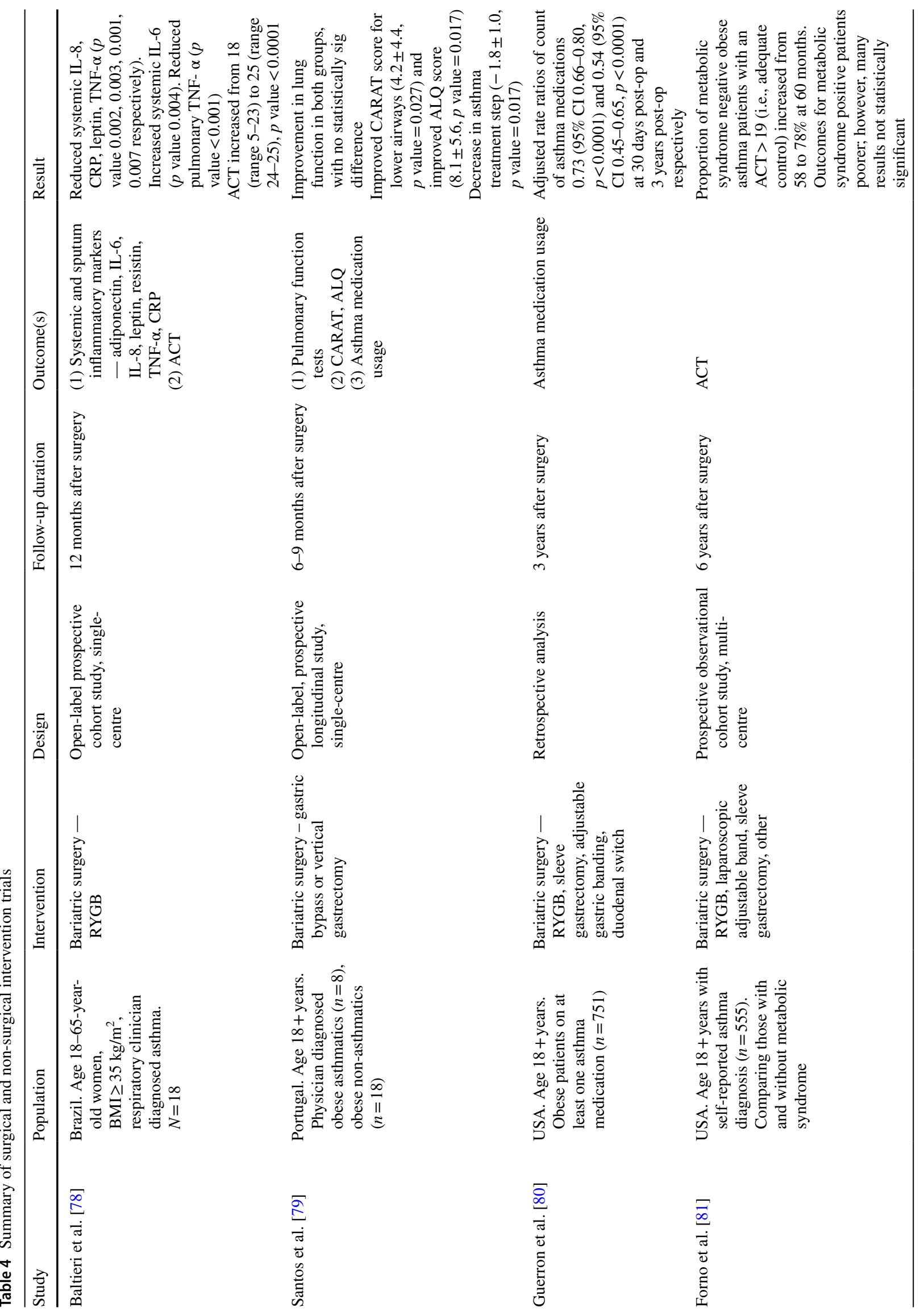




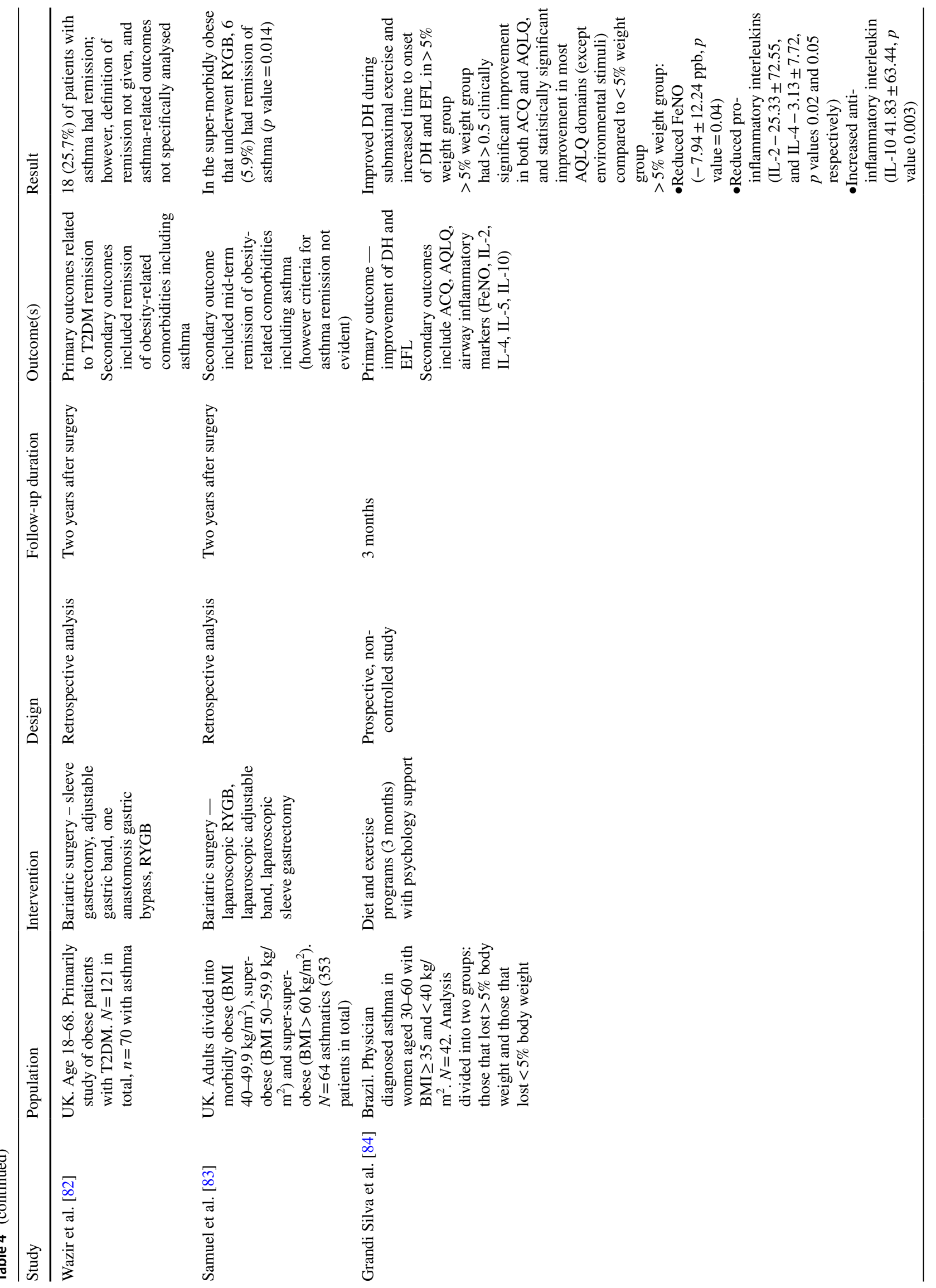




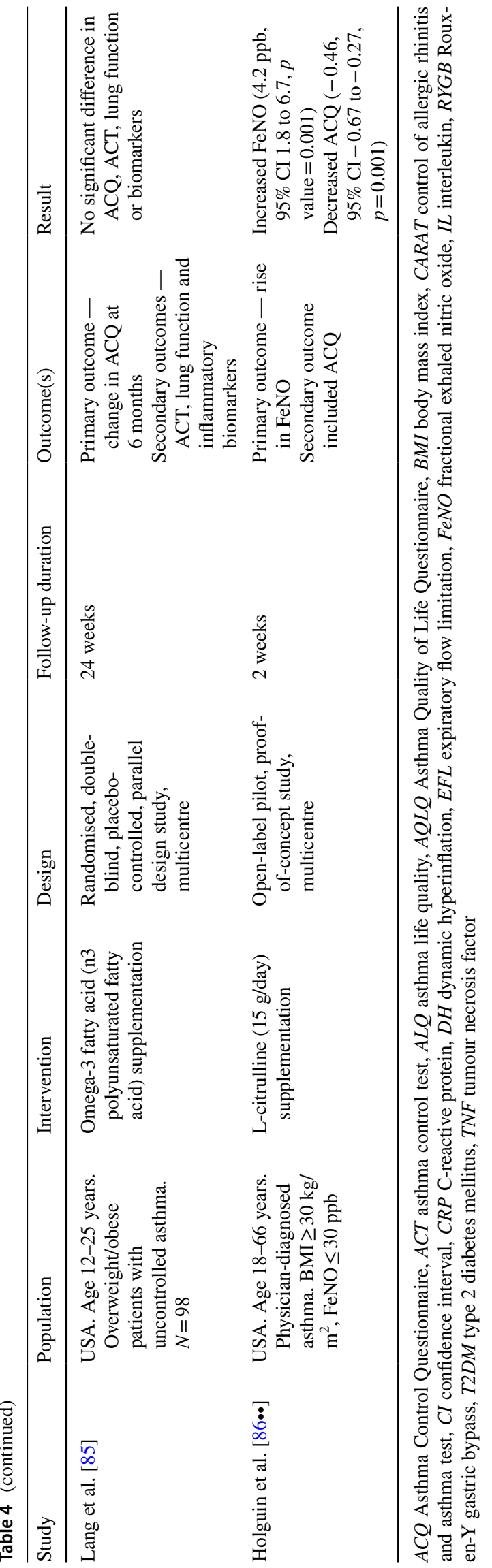

The impact of dietary factors on asthma is another area that is receiving interest. For example, high-fat and lowfibre intake have been linked to increasing airway inflammation [87]. Whilst robust evidence for treatments in this area is lacking, there is potential for future research. A pilot study of 41 obese adults with poorly controlled asthma demonstrated a decrease in ACQ, despite an increase in FeNO, with oral administration of $15 \mathrm{~g} /$ day L-citrulline supplements after 2 weeks [86••]. The authors suggest that obesity and asthma cause uncoupling of airway epitheliumbound nitric oxide synthase (NOS) causing reduced FeNO in this cohort, and that the increased FeNO seen postsupplementation is due to L-citrulline-mediated recoupling of NOS. This increase in FeNO might have suggested a deleterious effect on asthma outcomes; however, the improved ACQ implies otherwise, further highlighting the complexity of the obesity-inflammation relationship and a need for accurate obese-asthma specific biomarkers. The mean ACQ reduction of -0.46 , whilst statistically significant, failed to meet the minimal clinically important difference of 0.5 [88], but nevertheless, this proof-of-concept trial paves the way for a further suitably powered study. Conversely a doubleblind, multicentre, randomised, placebo-controlled trial [85] in adolescent obese asthma did not show any difference in asthma outcomes including biomarkers or lung function with omega-3 fatty acid supplementation although it is possible that higher doses and/or longer course of treatment may have led to more favourable effects.

Further research is needed to clarify the complex mechanisms that underlying the links between obesity and dietaryintake and inflammation in asthma. More evidence from randomised, controlled trials for weight loss in obese-asthma is needed, with pragmatic conservative strategies applicable to the real-world setting.

\section{Potential Treatments}

Whilst targeted therapies may be lacking, pursuing obesityinduced inflammation and repurposing current widely used anti-diabetic drugs for weight loss in obese asthma may pose a viable treatment option.

Recent randomised control trials in obese and healthyBMI adults with asthma $(n=127, n=23$ for two trials [89]) have contributed to the understanding of the interplay between airway inflammation and excessive dietary fatty acid and carbohydrate intake. Nucleotide-binding domain leucine-rich repeat and pyrin domain containing receptor 3 (NLRP3)-mediated airway inflammation was observed in healthy BMI individuals with asthma after over-nutrition, and enhanced NLRP3 inflammatory effects were identified in obese asthma participants, including higher levels of IL-5, IL-1 $\beta$, and sputum neutrophils. Findings suggest that 
targeting the NLRP3 inflammasome may yield a potential treatment in obese asthma [90].

Anti-diabetic medications that cause weight loss include metformin and glucagon-like peptide 1 agonists/receptor agonists. Neither of these are specific to diabetes, and both are beneficial for non-diabetic weight loss [91-93]. Whilst redirecting these medications to tackle the treatable trait of obesity in asthma might be of benefit, this remains to be proven. Nevertheless, preliminary studies do suggest that both metformin and GLP-1 agonists may improve asthma outcomes, independently of weight loss, perhaps due to underlying anti-inflammatory or immunomodulatory effects, or effects on insulin resistance [94, 95].

\section{Conclusion}

In summary, a better understanding of adipose tissue-associated inflammation and its relationship to asthma is needed. Obesityassociated asthma encompasses several endotypes and phenotypes in addition to the recently recognised adult-onset, femalepredominant, non-allergic obese-asthma phenomenon. The presence of metabolic syndrome is associated with increased morbidity and more difficult to treat disease. Currently available biomarkers may be of limited value in obesity-associated asthma, and identification of novel biomarkers is a priority for this difficult-to-treat subset of patients. Though real-world obesity-specific treatments are lacking, trials aiming at weight loss continue to show improvements and novel therapies for obese-asthma may be on the horizon.

\section{Compliance with Ethical Standards}

Conflict of Interest There are no conflicts of interest.

Human and Animal Rights and Informed Consent This article does not contain any studies with human or animal subjects performed by any of the authors.

Open Access This article is licensed under a Creative Commons Attribution 4.0 International License, which permits use, sharing, adaptation, distribution and reproduction in any medium or format, as long as you give appropriate credit to the original author(s) and the source, provide a link to the Creative Commons licence, and indicate if changes were made. The images or other third party material in this article are included in the article's Creative Commons licence, unless indicated otherwise in a credit line to the material. If material is not included in the article's Creative Commons licence and your intended use is not permitted by statutory regulation or exceeds the permitted use, you will need to obtain permission directly from the copyright holder. To view a copy of this licence, visit http://creativecommons.org/licenses/by/4.0/.

\section{References}

\section{Recent noteworthy papers have been highlighted as: · Important $\cdot \cdot$ Very important}

1. Global Initiative for Asthma. Global strategy for asthma management and prevention, 2020. Available from: https://www. ginasthma.org

2. Shah R, Hagell A, Cheung R. International comparisons of health and wellbeing in adolescence and early adulthood. Research report, Nuffield Trust and Association for Young People's Health. 2019 Feb. Retrieved from: https://www.nuffieldtrust.org.uk/research/ international-comparisons-of-health-and-wellbeing-in-adolescenceand-early-adulthood\#conclusion

3. Lancet T. Health and wellbeing in adolescence and early adulthood. Lancet. 2019;393(10174):847.

4. Taylor B, Mannino D, Brown C, et al. Body mass index and asthma severity in the National Asthma Survey. Thorax. 2008;63(1):14-20.

5. Sutherland ER, Goleva E, Strand M, et al. Body mass and glucocorticoid response in asthma. Am J Respir Crit Care Med. 2008;178(7):682-7.

6. Stanescu S, Kirby SE, Thomas M, et al. A systematic review of psychological, physical health factors, and quality of life in adult asthma. NPJ Prim Care Respir Med. 2019;29(1):37.

7. Klepaker G, Svendsen MV, Hertel JK, et al. Influence of obesity on work ability, respiratory symptoms, and lung function in adults with asthma. Respiration. 2019;98(6):473-81.

8. Luthe SK, Hirayama A, Goto T, et al. Association between obesity and acute severity among patients hospitalized for asthma exacerbation. J Allergy Clin Immunol Pract. 2018;6(6):1936-1941.e4.

9. Pate CA, Zahran HS, Bailey CM. Impaired health-related quality of life and related risk factors among US adults with asthma. J Asthma. 2019;56(4):431-9.

10. Oka S, Goto T, Hirayama A, Faridi MK, Camargo CA Jr, Hasegawa K. Association of obstructive sleep apnea with severity of patients hospitalized for acute asthma. Ann Allergy Asthma Immunol. 2020;124(2):165-170.e4.

11. World Health Organisation. 2020. Obesity and overweight. Retrieved from https://www.who.int/news-room/fact-sheets/detail/ obesity-and-overweight, Glasgow, UK.

12. Zammit C, Liddicoat H, Moonsie I, Makker H. Obesity and respiratory diseases. Int J Gen Med. 2010;3:335-43.

13. Baarnes CB, Thuesen BH, Linneberg A, Ulrik CS. Determinants of airflow limitation in Danish adults - findings from the Health 2006 cohort. Int J Chron Obstruct Pulmon Dis. 2019;26(14):713-8.

14. Kaminsky DA, Chapman DG, Holbrook JT, et al. Older age and obesity are associated with increased airway closure in response to methacholine in patients with asthma. Respirology. 2019;24(7):638-45.

15. Peters U, Subramanian M, Chapman DG, et al. BMI but not central obesity predisposes to airway closure during bronchoconstriction. Respirology. 2019;24(6):543-50.

16. Leishangthem GD, Mabalirajan U, Singh VP, et al. Ultrastructural changes of airway in murine models of allergy and diet-induced metabolic syndrome. ISRN Allergy. 2013;2013:261297.

17. Ricketts HC, Cowan DC. Asthma, obesity and targeted interventions: an update. Curr Opin Allergy Clin Immunol. 2019;19(1):68-74.

18. Sun YQ, Brumpton BM, Langhammer A, et al. Adiposity and asthma in adults: a bidirectional Mendelian randomisation 
analysis of The HUNT Study. Thorax. 2020;75(3):202-8. Noteworthy finding of a causal link between BMI and non-atopic asthma.

19. Abrahamsen R, Gundersen GF, Svendsen MV, et al. Possible risk factors for poor asthma control assessed in a cross-sectional population-based study from Telemark, Norway. PLoS One. 2020;15(5):e0232621.

20. Alves AM, Mello LM, Matos ASL, Cruz ÁA. Clinical features and associated factors with severe asthma in Salvador, Brazil. J Bras Pneumol. 2020;46(3):e20180341.

21. Souza ECC, Pizzichini MMM, Dias M, et al. Body mass index, asthma, and respiratory symptoms: a population-based study. J Bras Pneumol. 2019;46(1):e20190006.

22. Park S, Jung SY, Kwon JW. Sex differences in the association between asthma incidence and modifiable risk factors in Korean middle-aged and older adults: NHIS-HEALS 10-year cohort. BMC Pulm Med. 2019;19(1):248.

23. Lampalo M, Majer M, Ferara N, et al. Gender differences in relationship between body mass index and asthma. Psychiatr Danub. 2019;31(Suppl 5):786-91.

24. Zhu Z, Guo Y, Shi H, et al. Shared genetic and experimental links between obesity-related traits and asthma subtypes in UK Biobank. J Allergy Clin Immunol. 2020;145(2):537-49.

25. Borna E, Nwaru BI, Bjerg A, et al. Changes in the prevalence of asthma and respiratory symptoms in western Sweden between 2008 and 2016. Allergy. 2019;74(9):1703-15.

26. Irani C, Adib S, Halaby G, Sibai A. Obesity/overweight and asthma control in LEBANESE adults: a cross-sectional study. BMC Public Health. 2019;19(1):769.

27. Ohta K, Tanaka H, Tohda Y, et al. Asthma exacerbations in patients with asthma and rhinitis: Factors associated with asthma exacerbation and its effect on QOL in patients with asthma and rhinitis. Allergol Int. 2019;68(4):470-7.

28. Petermann-Rocha F, Rocha C, Martínez-Sanguinetti MA, et al. EN REPRESENTACIÓN DEL GRUPO ELHOC. ¿Existe asociación entre asma y adiposidad en la población adulta chilena? [Association between adiposity and asthma]. Rev Med Chil. 2019;147(6):733-740. Spanish

29. Xu S, Gilliland FD, Conti DV. Elucidation of causal direction between asthma and obesity: a bi-directional Mendelian randomization study. Int J Epidemiol. 2019;48(3):899-907.

30. Solet JL, Raherison-Semjen C, Mariotti E, et al. A cross sectional survey to estimate prevalence and associated factors of asthma on Reunion Island, Indian Ocean. BMC Public Health. 2019;19(1):663.

31. Neffen $\mathrm{H}$, Chahuàn $\mathrm{M}$, Hernández $\mathrm{DD}$, et al. Key factors associated with uncontrolled asthma - the Asthma Control in Latin America Study. J Asthma. 2020;57(2):113-22.

32.• Vandenplas O, Godet J, Hurdubaea L, et al; European network for the PHenotyping of OCcupational ASthma (E-PHOCAS) investigators. Severe occupational asthma: insights from a multicenter European cohort. J Allergy Clin Immunol Pract. 2019;7(7):2309-2318.e4. Novel insight of risk factors for occupational asthma identifying obesity among others.

33. Aarab R, Vijverberg SJH, Prins M, et al. Prevalence of and factors associated with adult-onset asthma in different ethnic groups: The HELIUS study. Respir Med. 2019;150:113-9.

34. Lurbet MF, Rojano B, Whittaker Brown SA, et al. Obesity trends among asthma patients in the United States: a populationbased study. Ann Glob Health. 2019;85(1):11.

35. Tomita Y, Fukutomi Y, Irie M, et al. Obesity, but not metabolic syndrome, as a risk factor for late-onset asthma in Japanese women. Allergol Int. 2019;68(2):240-6.

36. Santos FMD, Viana KP, Saturnino LT, et al. Trend of selfreported asthma prevalence in Brazil from 2003 to 2013 in adults and factors associated with prevalence. J Bras Pneumol. 2018;44(6):491-497

37. Matulonga-Diakiese B, Courbon D, Fournier A, et al. Risk of asthma onset after natural and surgical menopause: results from the French E3N cohort. Maturitas. 2018;118:44-50.

38. Tay TR, Choo XN, Yii A, et al. Asthma phenotypes in a multiethnic Asian cohort. Respir Med. 2019;157:42-8.

39. Wu W, Bang S, Bleecker ER, et al. Multiview cluster analysis identifies variable corticosteroid response phenotypes in severe asthma. Am J Respir Crit Care Med. 2019;199(11):1358-67.

40. Hsiao HP, Lin MC, Wu CC, et al. Sex-specific asthma phenotypes, inflammatory patterns, and asthma control in a cluster analysis. J Allergy Clin Immunol Pract. 2019;7(2):556-567.e15.

41.• Han YY, Forno E, Celedón JC. Sex steroid hormones and asthma in a nationwide study of U.S. adults. Am J Respir Crit Care Med. 2020;201(2):158-166. Novel finding of the impact of sex steroids combined with obesity on asthma.

42.• Michalovich D, Rodriguez-Perez N, Smolinska S, et al. Obesity and disease severity magnify disturbed microbiome-immune interactions in asthma patients. Nat Commun. 2019;10(1):5711. First study to assess the impact of the gut microbiome in conjunction with obesity on asthma, with subsequent practical therapeutic implications.

43.• Sunadome H, Matsumoto H, Izuhara Y, et al. Correlation between eosinophil count, its genetic background and body mass index: The Nagahama Study. Allergol Int. 2020;69(1):46-52. GWAS showing heterogeneous effects of obesity on eosinophils.

44. Farahi N, Loutsios C, Tregay N, et al. In vivo imaging reveals increased eosinophil uptake in the lungs of obese asthmatic patients. J Allergy Clin Immunol. 2018;142(5):1659-1662.e8.

45. Rutting S, Zakarya R, Bozier J, Xenaki D, Horvat JC, Wood LG, Hansbro PM, Oliver BG. Dietary fatty acids amplify inflammatory responses to infection through p38 MAPK signaling. Am J Respir Cell Mol Biol. 2019;60(5):554-68.

46. Pampuch A, Milewski R, Rogowska A, Kowal K. Predictors of airway hyperreactivity in house dust mite allergic patients. Adv Respir Med. 2019;87(3):152-8.

47. Orfanos S, Jude J, Deeney BT, et al. Obesity increases airway smooth muscle responses to contractile agonists. Am J Physiol Lung Cell Mol Physiol. 2018;315(5):L673-81.

48. Goudarzi H, Konno S, Kimura H, et al; Hi-CARAT investigators. Impact of abdominal visceral adiposity on adult asthma symptoms. J Allergy Clin Immunol Pract. 2019;7(4):1222-1229.e5

49. Wu TD, Brigham EP, Keet CA, et al. Association between prediabetes/diabetes and asthma exacerbations in a claims-based obese asthma cohort. J Allergy Clin Immunol Pract. 2019;7(6):1868-1873.e5

50. Sadeghimakki R, McCarthy HD. Interactive effects of adiposity and insulin resistance on the impaired lung function in asthmatic adults: cross-sectional analysis of NHANES data. Ann Hum Biol. 2019;46(1):56-62.

51. Jung SM, Sanchez-Gurmaches J, Guertin DA. Brown adipose tissue development and metabolism. Handb Exp Pharmacol. 2019;251:3-36.

52. Hildebrand S, Stümer J, Pfeifer A. PVAT and Its relation to brown, beige, and white adipose tissue in development and function. Front Physiol. 2018;9:70.

53. Kiefer FW. The significance of beige and brown fat in humans. Endocr Connect. 2017;6(5):R70-9.

54. Shimizu I, Aprahamian T, Kikuchi R, et al. Vascular rarefaction mediates whitening of brown fat in obesity. J Clin Invest. 2014;124(5):2099-112.

55. Kotzbeck P, Giordano A, Mondini E, et al. Brown adipose tissue whitening leads to brown adipocyte death and adipose tissue inflammation. J Lipid Res. 2018;59(5):784-94.

56. Nishimura S, Manabe I, Nagai R. Adipose tissue inflammation in obesity and metabolic syndrome. Discov Med. 2009;8(41):55-60. 
57. Adami GF, Carbone F, Montecucco F, et al. Adipose tissue composition in obesity and after bariatric surgery. Obes Surg. 2019;29(9):3030-8.

58. Liang W, Ye DD. The potential of adipokines as biomarkers and therapeutic agents for vascular complications in type 2 diabetes mellitus. Cytokine Growth Factor Rev. 2019;48:32-9.

59. Kwon H, Pessin JE. Adipokines mediate inflammation and insulin resistance. Front Endocrinol (Lausanne). 2013;4:71.

60. Pereira S, Alvarez-Leite J. Adipokines: biological functions and metabolically healthy obese profile. Journal of Receptor, Ligand and Channel Research. 2014;7:15-25.

61. Leon-Cabrera S, Arana-Lechuga Y, Esqueda-León E, et al. Reduced systemic levels of IL-10 are associated with the severity of obstructive sleep apnea and insulin resistance in morbidly obese humans. Mediators Inflamm. 2015;2015:493409

62. Esposito K, Pontillo A, Giugliano F, et al. Association of low interleukin-10 levels with the metabolic syndrome in obese women. J Clin Endocrinol Metab. 2003;88(3):1055-8.

63. Dias ASO, Santos ICL, Delphim L, et al. Serum leptin levels correlate negatively with the capacity of vitamin $\mathrm{D}$ to modulate the in vitro cytokines production by $\mathrm{CD} 4<\sup >+</ \sup >\mathrm{T}$ cells in asthmatic patients. Clin Immunol. 2019;205:93-105.

64. White SR, Laxman B, Naureckas ET, et al. Evidence for an IL6-high asthma phenotype in asthmatic patients of African ancestry. J Allergy Clin Immunol. 2019;144(1):304-306.e4.

65. Li Z, Leynaert B, Dumas O, et al. Role of leptin in the association between body adiposity and persistent asthma: a longitudinal study. Obesity (Silver Spring). 2019;27(6):894-8.

66. McGregor MC, Krings JG, Nair P, Castro M. Role of biologics in asthma. Am J Respir Crit Care Med. 2019;199(4):433-45.

67. Doroudchi A, Pathria M, Modena BD. Asthma biologics: comparing trial designs, patient cohorts and study results. Ann Allergy Asthma Immunol. 2020;124(1):44-56.

68. Komakula $\mathrm{S}$, Khatri $\mathrm{S}$, Mermis J, et al. Body mass index is associated with reduced exhaled nitric oxide and higher exhaled 8-isoprostanes in asthmatics. Respir Res. 2007;8(1):32.

69. Barros R, Moreira A, Fonseca J, et al. Obesity and airway inflammation in asthma. J Allergy Clin Immunol. 2006;117(6):1501-2.

$70 . \bullet$ Winnica D, Corey C, Mullett S, et al. Bioenergetic differences in the airway epithelium of lean versus obese asthmatics are driven by nitric oxide and reflected in circulating platelets. Antioxid Redox Signal. 2019;31(10):673-86. Important insights into the effects of obesity on airway nitric oxide synthase uncoupling impacting FeNO interpretation in obese asthma patients.

71.• Lugogo N, Green CL, Agada N, et al. Obesity's effect on asthma extends to diagnostic criteria. J Allergy Clin Immunol. 2018;141(3):1096-104. Novel finding of obesity affecting asthma biomarker levels with suggestion of lower thresholds needed in obese asthma patients.

72. Israel E, Reddel HK. Severe and difficult-to-treat asthma in adults. N Engl J Med. 2017;377(10):965-76.

73. Sze E, Bhalla A, Nair P. Mechanisms and therapeutic strategies for non-T2 asthma. Allergy. 2020;75(2):311-25.

74. Peters MC, Ringel L, Dyjack N, et al. A transcriptomic method to determine airway immune dysfunction in T2-high and T2-low asthma. Am J Respir Crit Care Med. 2019;199(4):465-77.

75. Mogensen I, James A, Malinovschi A. Systemic and breath biomarkers for asthma: an update. Curr Opin Allergy Clin Immunol. 2020;20(1):71-9.

76. Farah CS. Airways wide shut: A physiological phenotype of asthma? Respirology. 2019;24(7):616-7.

77. Welbourn R, Hopkins J, Dixon JB, et al; Guidance gevelopment group. Commissioning guidance for weight assessment and management in adults and children with severe complex obesity. Obes Rev. 2018;19(1):14-27.
78. Baltieri L, Cazzo E, de Souza AL, et al. Influence of weight loss on pulmonary function and levels of adipokines among asthmatic individuals with obesity: One-year follow-up. Respir Med. 2018:145:48-56.

79. Santos LM, Ramos B, Almeida J, et al. The impact of weight loss beyond lung function: benefit with respect to asthma outcomes. Pulmonology. 2019;25(6):313-319

80. Guerron $\mathrm{AD}$, Ortega $\mathrm{CB}$, Lee $\mathrm{HJ}$, et al. Asthma medication usage is significantly reduced following bariatric surgery. Surg Endosc. 2019;33(6):1967-75.

81. Forno E, Zhang P, Nouraie M, et al. The impact of bariatric surgery on asthma control differs among obese individuals with reported prior or current asthma, with or without metabolic syndrome. PLoS One. 2019;14(4):e0214730

82. Wazir N, Arshad MF, Finney J, et al. Two years remission of type 2 diabetes mellitus after bariatric surgery. J Coll Physicians Surg Pak. 2019;29(10):967-71.

83. Samuel N, Jalal Q, Gupta A, et al. Mid-term bariatric surgery outcomes for obese patients: does weight matter? Ann R Coll Surg Engl. 2020;102(1):54-61.

84. Grandi Silva A, Duarte Freitas P, Ferreira PG, et al. Effects of weight loss on dynamic hyperinflation in obese women asthmatics. J Appl Physiol (1985). 2019;126(2):413-421

85. Lang JE, Mougey EB, Hossain MJ, et al. Fish oil supplementation in overweight/obese patients with uncontrolled asthma. A randomized trial. Ann Am Thorac Soc. 2019;16(5):554-562

86.•Holguin F, Grasemann H, Sharma S, et al. L-Citrulline increases nitric oxide and improves control in obese asthmatics. JCI Insight. 2019;4(24):e131733. Important proof-of-concept study highlighting nitric oxide synthase recoupling as a potential therapeutic mechanism and the effect of obesity on FeNO levels.

87. Alwarith J, Kahleova H, Crosby L, et al. The role of nutrition in asthma prevention and treatment. Nutr Rev. 2020;78(11):928-38.

88. Juniper EF, Svensson K, Mörk AC, Ståhl E. Measurement properties and interpretation of three shortened versions of the asthma control questionnaire. Respir Med. 2005;99(5):553-8.

89. Wood LG, Li Q, Scott HA, et al. Saturated fatty acids, obesity, and the nucleotide oligomerization domain-like receptor protein 3 (NLRP3) inflammasome in asthmatic patients. J Allergy Clin Immunol. 2019;143(1):305-15.

90. Jeong A, Imboden M, Ghantous A, et al. DNA methylation in inflammatory pathways modifies the association between BMI and adult-onset non-atopic asthma. Int J Environ Res Public Health. 2019;16(4):600

91. Yerevanian A, Soukas AA. Metformin: mechanisms in human obesity and weight loss. Curr Obes Rep. 2019;8(2):156-64.

92. Pi-Sunyer X, Astrup A, Fujioka K, et al. A randomised, controlled trial of $3.0 \mathrm{mg}$ of liraglutide in weight management. $\mathrm{N}$ Engl $\mathrm{J}$ Med. 2015;373:11-22.

93. Wilding JPH, Batterham RL, Calanna S, et al. Once-weekly semaglutide in adults with overweight or obesity. N Engl J Med. 2021. https://doi.org/10.1056/NEJMoa2032183. Epub ahead of print.

94. Rastogi D. Evidence builds for a role of metformin in asthma management. Ann Am Thorac Soc. 2019;16(12):1497-9.

95. Nguyen DV, Linderholm A, Haczku A, Kenyon N. Glucagon-like peptide 1: a potential anti-inflammatory pathway in obesity-related asthma. Pharmacol Ther. 2017;180:139-43.

Publisher's Note Springer Nature remains neutral with regard to jurisdictional claims in published maps and institutional affiliations. 